\title{
KARAKTERISASI SENSOR POLIMER KONDUKTIF POLIANILIN BERPENGISI SERBUK BAN UNTUK MENDETEKSI KONDUKTIVITAS MINYAK
}

\author{
Rizky Dharmawan, Satriaji Sudigdo, Hamidah Harahap \\ Departemen Teknik Kimia, Fakultas Teknik, Universitas Sumatera Utara, \\ Jl. Almamater Kampus USU Medan 20155, Indonesia \\ Email: rizkydharmawan09@gmail.com
}

\begin{abstract}
Abstrak
Sensor polimer konduktif dengan variasi komposisi dari polianilin dan serbuk ban dan 1,4-metil-pyrrolidinone sebagai pelarut menggunakan proses polimerisasi telah dilakukan. Proses polimerisasi disiapkan pada suhu $100^{\circ} \mathrm{C}$ dalam air mendidih selama 30 menit. Dilakukan beberapa jenis analisa terhadap sensor polimer konduktif antara lain konduktivitas listrik, Scanning Electron Microscope, Fourier Transform Infra-Red (FTIR), dan X-Ray Diffraction (XRD). Tes yang dilakukan menggunakan beberapa jenis minyak (sawit, jagung, solar, dan oli mesin). Hasil penelitian menunjukkan bahwa konduktivitas listrik yang paling tinggi untuk sensor-4 (20 phr dari serbuk ban) pada $80^{\circ} \mathrm{C}$ selama 30 menit. Hasil pemindaian mikroskop elektron menunjukkan permukaan yang kasar dan tersebar merata. Analisis XRD menunjukkan bahwa sensor memiliki struktur kristalografi face center cubic (FCC). Konduktivitas listrik paling optimum dari sensor adalah dapat mendeteksi konduktifitas dari minyak kelapa sawit. Sensor memberikan respon yang paling baik terhadap minyak sawit (Neptune) dibandingkan dengan minyak jagung (vecorn), minyak solar, dan oli mesin.
\end{abstract}

Kata kunci : Polianilin, serbuk ban, konduktifitas, sensor polimer konduktif, minyak kelapa sawit

\begin{abstract}
Conductive polymer sensor with varying amounts of poly aniline and tire dust and 1.4-methyl-pyrrolidinone as solvent using polymerization process have been developed. The polymerization process was prepared at temperature $100^{\circ} \mathrm{C}$ in the boiling water at 30 minutes. Conductive polymer sensor is undergone several type of the analysis including electrical conductivity, Scanning Electron Microscope, Fourier Transform Infra-Red (FTIR), X-Ray Diffraction (XRD). The test used some kind of oil (palm oil, corn oil, diesel oil, and engine oil). The result showed that the highest electrical conductivity for the sensor-4 (20 per hundred resin of the tire dust) at $80^{\circ} \mathrm{C}$ for 30 minutes. Scanning electron microscope result shows rough surface and well dispersed of the tire dust in poly aniline / tire dust conductive blends. The analysis of X-RD shows the face center cubic (FCC) crystallographic structure of the sensor. The optimum of the electrical conductivity of the sensor was applied to detect the palm oil. The sensor given response towards palm oil (Neptune) compered to corn oil, diesel oil, and engine oil.
\end{abstract}

Keyword: Poly aniline, tire dust, conductive polymer sensor, sensor, palm oil

\section{Pendahuluan}

Polimer konduktif pertama kali diidentifikasi pada tahun 1980 dan termasuk dalam kelas bahan organik yang dapat disintesis elektrokimia dari monomer yang sesuai dan heterosiklik aromatik. Dewasa ini polimer organik konduktif telah menarik perhatian yang cukup besar dalam 15 tahun terakhir. Kemampuan menghantarkan listrik dari polimer adalah hal baru yang menggabungkan antara atribut fisik dan kimia dari plastik (polimer) dengan sifat elektronik dari logam [3].

Keuntungan dari polimer organik konduktif dibandingkan dengan bahan anorganik yang digunakan sampai sekarang adalah keanekaragaman mereka, sintesis yang mudah, dan terutama sensitivitas mereka pada suhu kamar [4].

\section{Teori}

Pembuatan polimer konduktif dapat dilakukan baik secara kimia atau elektrokimia.
Di antara polimer organik konduktif yang ada, polianilin menempati tempat yang penting karena adanya kemampuan spesifik, karakteristik konduktivitas, serta penerapannya dalam perangkat elektronik dan sensor yang sangat fleksibel [5].

Polianilin telah banyak diteliti sebagai bahan potensial yang digunakan untuk aplikasi gas penginderaan (sensor gas), karena konduktivitas listriknya yang dapat dikendalikan, stabilitas lingkungan dan sifat redoks yang terkait dengan rantai nitrogen [6].

Serbuk ban atau yang sering disebut dengan "tire dust" atau "crumb rubber" adalah bahan buangan sisa roda ban modern yang terdiri dari seutas gabungan cord/rubber. Ban roda yang dihasilkan dari beberapa komponen -komponen yang terpisah, seperti innerliner, dawai dan kabel, sabuk-sabuk dan lain-lain serta komponen yang berbeda mempunyai komposisi-komposisi karet yang berbeda [1]. 


\section{Bahan - Bahan}

Bahan-bahan kimia yang digunakan antara lain; polianilin, serbuk ban dengan ukuran 80 mesh, 1,4-metil pyrlidinone, epoksi, pengeras (hardener), yang diperoleh dari Sigma Aldrich Pulau Penang. Untuk bahan PCB dan kabel diperoleh dari Laboraturium Sensor University Malaysia Perlis.

\section{Metodologi Pembuatan Sensor}

PANI (polianilin) dengan berat 0,2 gram dicampur dengan $5 \mathrm{phr}$ (per hundred resin) serbuk ban pada beaker glass. Ditambahkan $10 \mathrm{ml}$ 1,4-metil piroledinone. Campuran tersebut kemudian diaduk selama 25 menit diatas penangas air. Campuran kemudian dicampur dengan epoxyhardener dan diaduk campurannya sehingga homogen. Campuran yang homogen kemudian diletakkan sebanyak $1 \mathrm{ml}$ pada PCB. Campuran yang telah melekat pada PCB itu kemudian dipanaskan dalam oven pada berbagai rentang suhu, yaitu 70, 80, dan $90^{\circ} \mathrm{C} \quad$ selama 20, 30, 40 menit. Setelah dikeluarkan dari oven, sensor didiamkan (posting-curing) pada sampel selama 24 jam pada suhu kamar dan selanjutnya ditambahkan kabel pada PCB dengan dua kutub anoda dan katoda. Formulasi dari bahan pembuatan sensor ditunjukkan dalam Tabel 1.

Tabel 1. Formulasi Bahan Pembuatan Sensor

\begin{tabular}{cccc}
\hline $\begin{array}{c}\text { Jenis } \\
\text { Sensor }\end{array}$ & $\begin{array}{c}\text { Polianilin } \\
\text { (gram) }\end{array}$ & $\begin{array}{c}\text { Serbuk } \\
\text { Ban } \\
\text { (phr) }\end{array}$ & $\begin{array}{c}\text { Epoxy- } \\
\text { hardener } \\
\text { (ml) }\end{array}$ \\
\hline Sensor -0 & 0,2 & 0 & 3 \\
Sensor -1 & 0,2 & 5 & 3 \\
Sensor -2 & 0,2 & 10 & 3 \\
Sensor -3 & 0,2 & 15 & 3 \\
Sensor -4 & 0,2 & 20 & 3 \\
Sensor -5 & 0,2 & 25 & 3 \\
\hline
\end{tabular}

\section{Analisa Konduktifitas Sensor}

Sensor dihubungkan ke multimeter. lalu di ukur nilai resistansi pada alat multimeter. Dicatat hasil yang diperoleh. Hasil analisa bilangan resistansi sensor yaitu menghubungkan dengan ASTM D257, dimana dapat dituliskan seperti persamaan 1:

$$
\sigma=\frac{T}{R \times A}
$$

Dimana: $\quad \sigma=$ Nilai konduktivitas sensor $\mathrm{T}=$ Ketebalan dari PVC sensor

$\mathrm{R}=$ Nilai resistansi sensor $\mathrm{A}=$ Luas permukaan sensor
Analisa Gugus Fungsi Menggunakan FTIR

Sensor dimasukkan ke dalam alat FT-IR Dihitung panjang gelombang dengan menggunakan alat FT-IR tersebut. Resolusi spektrum yang dipilih dan jangkauan pemindaian adalah $4 \mathrm{~cm}^{-1}$ dan $600-4000 \mathrm{~cm}^{-1}$.

\section{Analisa Morfologi Permukaan Sensor}

Morfologi permukaan sensor diteliti dengan menggunakan mikroskop elektron scanning Model Joel JSM 6460LA. Sebelum pemeriksaan SEM, sampel yang dipasang di alas aluminium dan dibiarkan dalam tutup sputtering yaitu, sebuah lapisan paladium tipis $20 \mathrm{~nm}$.

\section{Analisa X-Ray Diffraction (XRD)}

Analisa XRD pada sensor konduktif polimer dilakukan menggunakan XRD 6000 jenis Shimadzu pada voltase $35 \mathrm{kV}, 25 \mathrm{~mA}$, dan radiasi $\mathrm{Cu}(\mathrm{Cu}=1,54 \AA)$. Pancaran dijalankan dalam rentang $10-80$ (20). Analisa ini dilakukan pada suhu kamar mengunakan kecepatan sinar pada $5^{\circ} \mathrm{C} /$ menit.

\section{Hasil dan pembahasan}

Berdasarkan hasil pengukuran nilai konduktivitas diperoleh kondisi proses yang terbaik dalam pembuatan sensor polimer konduktif. Nilai konduktivitas tertinggi diperoleh pada temperatur $80{ }^{\circ} \mathrm{C}$ dengan waktu 30 menit.

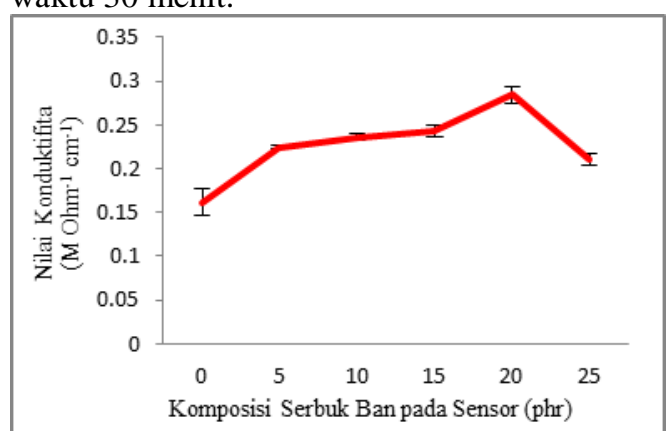

Gambar 1. Pengaruh Kandungan Serbuk Ban Terhadap Konduktivitas Sensor

Dari Gambar 1 terlihat bahwa dari sensor 0 sampai kepada sensor dengan komposisi serbuk ban sebanyak 20 phr nilai konduktivitas semakin meningkat, dan menurun pada sensor 25 phr. Peningkatan nilai konduktivitas ini disebabkan karena kandungan karbon hitam (carbon black) yang ada pada serbuk ban menyebabkan elektron yang ada pada polianilin lebih mudah untuk melakukan lompatan elektron disepanjang rantai polimer tersebut (polianilin) [7] Sedangkan menurun nya konduktivitas sensor pada komposisi 25 phr adalah disebabkan karena serbuk ban yang berikatan dengan matriks polianilin mengalami kejenuhan, 
sehingga sulit untuk melakukan lompatan elektron.

Analisa gugus fungsi dari sensor dilakukan dengan alat FTIR.

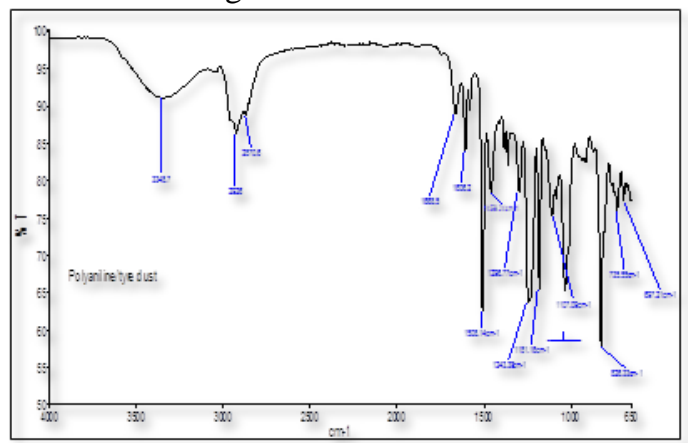

\section{Gambar 2. Hasil Spektrum Sensor}

Gambar 2 menunjukkan puncak-puncak panjang gelombang yang dihasilkan oleh alat FTIR untuk sensor dengan kondungan serbuk ban $20 \mathrm{phr}$ dan kondisi operasi $80^{\circ} \mathrm{C}$ selama 30 menit. Pada panjang gelombang 3348,7 $\mathrm{cm}^{-1}$ adalah gugus $\mathrm{OH}$ (hidroksil) dari bahan additif yang terdapat dalam serbuk ban. Penyerapan pada panjang gelombang 2926 $\mathrm{cm}^{-1}$ dan 2870,6 $\mathrm{cm}^{-1}$ menunjukkan serapan $\mathrm{C}-\mathrm{H}, \quad \mathrm{C}-\mathrm{H}_{3}$, dan $-\mathrm{C}-\mathrm{H}_{2}$, Ini membuktikan bahwa serapan-serapan pada panjang gelombang tersebut adalah berasal dari polimer konduktif. Pada serapan dengan panjang gelombang 1668,5; 1606,2; 1508,14; dan $1458,24 \mathrm{~cm}^{-1}$ menunjukkan gugus $\mathrm{C}=\mathrm{C}$ (ikatan rangkap karbon) dari struktur benzene didalam poli anilin. Serapan pada panjang gelombang 1296,77 $\mathrm{cm}^{-1}$ menunjukkan vibrasi $\mathrm{CH}_{2}$ dan $\mathrm{CH}_{3}$. Pada serapan panjang gelombang 1243,39 $\mathrm{cm}^{-}$menunjukkan gugus fungsi N-H (amina primer) dari poli anilin. Pada serapan dengan panjang gelombang 1181,16; dan 1107,09 $\mathrm{cm}^{-1}$ menunjukkan ikatan dari CN. Pada serapan dengan panjang gelombang 735,55; dan $697,21 \mathrm{~cm}^{-1}$ menunjukkan $\mathrm{C}-\mathrm{H}$ yang out of plan [2].

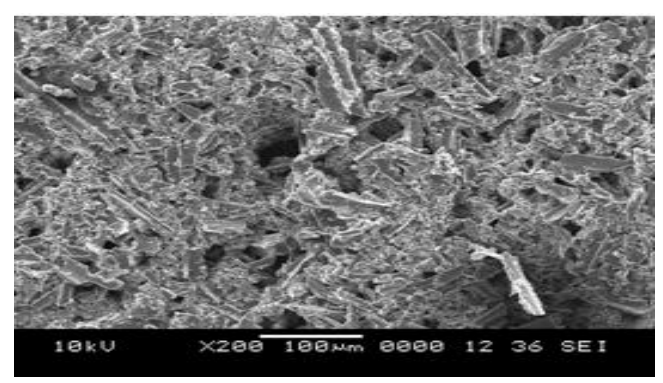

Gambar 3. Hasil Analisa SEM dengan Perbesaran $200 \times$ pada Temperatur $80^{\circ} \mathrm{C}$ pada Waktu 30 Menit

Gambar 3 merupakan hasil dari analisa morfologi permukaan sensor polianilin berpengisi serbuk ban yang telah dianalisa dengan menggunakan Scanning Electron Microscopy (SEM) dengan menggunakan perbesaran $200 \mathrm{x}$ pada kondisi proses $80^{\circ} \mathrm{C}$ selama 30 menit. Dari hasil terlihat bahwa serbuk ban yang terkandung dalam sensor terdistribusi secara merata, yaitu tidak ada bagian sensor yang kosong, karena komposisi serbuk ban tersebar secara merata mengakibatkan matriks dan serbuk ban semakin mudah untuk melakukan proses lompatan elektron sehingga sensor menghasilkan konduktivitas yang tinggi.

Karakteristik struktur dari sensor yang diproses pada suhu $80^{\circ} \mathrm{C}$ dalam waktu 30 menit telah dianalisa dengan instrumen $X$-Ray Diffraction seperti yang terlihat pada gambar 4. Struktur partikel kristal dapat terlihat berdasarkan ketinggian dan ketajaman dari puncak yang terbaca dalam alat [7].

Seluruh puncak digunakan untuk menentukan pola-pola yang akan digunakan untuk melihat jenis struktur kristal pada sistem kubik yang terbentuk dari komposit polianilin berpengisi serbuk ban. Selanjutnya, puncakpuncak yang terbaca akan di hitung berdasarkan indeks Miller yang ditunjukkan pada persamaan 2 :

$$
\mathrm{n} \times \lambda=2 \mathrm{~d} \sin \theta .
$$

Dimana: $d=$ jarak antara atom

$\mathrm{n}=$ tingkat refleksi

$\lambda=$ panjang gelombang dari radiasi $(1,54 \AA)$

$\theta=$ sudut yang terbentuk

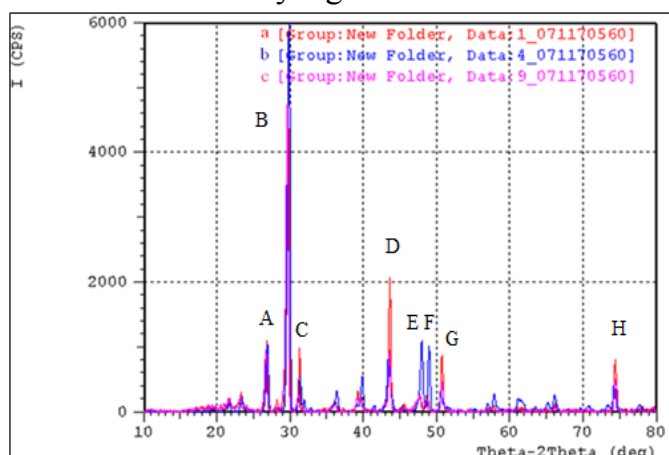

Gambar 4. Hasil Difraktogram Analisa $X$ -

\section{Ray Diffraction Sensor}

Berdasarkan hasil dari difraktogram dan juga perhitungan dari jarak interplanar, susunan polanya menunjukkan sensor yang dihasilkan memiliki struktur FCC (face centered cubic), yaitu pada grafik terlihat bahwa komposit tersebut memiliki daerah kristal yang ditunjukkan oleh puncak yang terbentuk.

Analisa konduktivitas pada minyak dilakukan dengan menggunakan bebrapa jenis minyak seperti minyak goreng kelapa sawit dengan merek dagang Neptune, minyak 
jagung dengan merek dagang Vecorn, minyak solar, dan oli. Analisa ini dilakukan dengan menggunakan temperature kamar $\left(30^{\circ} \mathrm{C}\right)$.

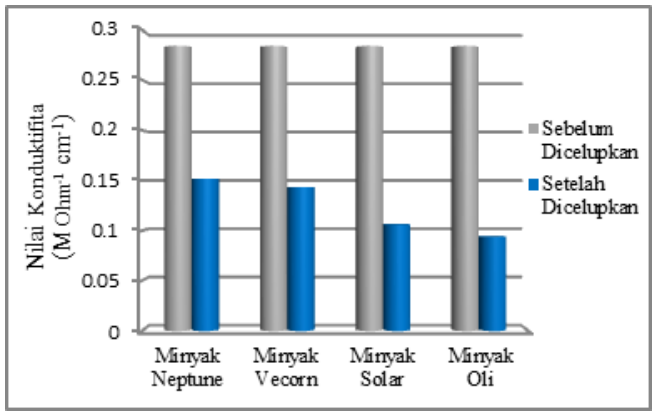

Gambar 5. Hasil Konduktivitas Minyak

Dari gambar 5 terlihat bahwa minyak dapat terdeteksi dengan menggunakan sensor polimer konduktif ini. Hal ini disebabkan karena sensor yang dihasilkan merupakan campuran dari senyawa polianilin yang bersifat hidrofilik dengan serbuk ban yang bersifat hidrofobik, sehingga sensor ini dapat digunakan untuk mendeteksi senyawa minyak yang merupakan hidrofobik. Sensor pada penelitian ini memiliki kereaktifan yang lebih baik untuk digunakan pada minyak jagung dan juga minyak sawit. Hal ini dipengaruhi oleh ikatan rantai karbon yang terdapat pada masing-masing minyak. Minyak goreng sawit dan jagung memiliki ikatan rantai karbon yang lebih pendek daripada minyak diesel dan juga oli.

Komposit yang dihasilkan akan bereaksi dengan senyawa karbon untuk membentuk senyawa radikal yang akhirnya akan terjadi lompatan elektron pada ikatan rantai karbon di dalam minyak tersebut. Oleh karena itu, semakin pendek ikatan rantai karbon yang ada maka lompatan elektron akan semakin mudah untuk terjadi. Akan tetapi, sensor yang berasal dari polianilin berpengisi serbuk ban memiliki kereaktifan yang lebih dalam hal mendeteksi konduktivitas minyak kelapa sawit, Hal ini sesuai dengan konduktivitas tertinggi ditunjukkan oleh minyak kelapa sawit sebesar $15179 \mathrm{M} \mathrm{Ohm}^{-1} \mathrm{~cm}^{-1}$. Oleh karena itu, sensor ini lebih sesuai untuk mendeteksi minyak kelapa sawit.

\section{Kesimpulan}

Sensor konduktivitas tertinggi adalah sensor dengan kandungan serbuk ban $20 \mathrm{phr}$ dengan suhu pemrosesan $80^{\circ} \mathrm{C}$ selama 30 menit, dengan nilai konduktivitas $0,284003 \mathrm{M}$ $\mathrm{ohm}^{-1} \mathrm{~cm}^{-1}$. Dari hasil analisa FT-IR terlihat gugus-gugus fungsi yang reaktif dan menunjukkan interaksi antara matriks dan pengisi secara fisik. Dari uji XRD diketahui bahwa sensor yang dihasilkan memiliki struktur kristalin FCC (Face Center Cubic) pada permukaannya. Sensor yang dibuat lebih reaktif terhadap minyak goreng kelapa sawit dengan konduktivitas sebesar $0,15179 \mathrm{M}$ $\mathrm{Ohm}^{-1} \mathrm{~cm}^{-1}$.

\section{Daftar pustaka}

[1] Juli Harni, 2011, Pembuatan dan Karakterisasi Genteng Polimer Menggunakan Bahan Aspal dengan Campuran Serbuk Ban Bekas dan Polipropilen Bekas, Departemen Fisika. Fakultas Ilmu Matematika dan Ilmu Pengetahuan Alam. Medan : Universitas Sumatera Utara.

[2] Pavia Donald L, Gary M. Lampman, George S. Kriz. 2001. Introduction to Spectroscopy. Third Edition. Thomson Learning, Inc. United State of America.

[3] Saboktakin, M.R ,dkk. 2009, Syinthetic, and Charactherization Polyaniline/Poly (P-Hydroxyaniline) $\quad / \mathrm{Fe}_{3} \mathrm{O}_{4} \quad$ Magnetic Nanocomposite. Baku State University. Azerbaijan.

[4] Schöllhorn, Germain J.P., Pauly A., Maleysson C., Blanc J.P. 1998. Influence of peripheral electron-withdrawing substituents on the conductivity of zinc phthalocyanine in the presence of gases. Bagian 1: reducing gases. Thin Solid Films, 326, Halaman 245-250.

[5] Sertova N, Geffroy B, Nunzi J.M, Petkov I. (1998). PVC as photodonor of $\mathrm{HCl}$ for protonation of polyaniline. Journal of Photochemistry and Photobiology A: Chemistry, 113, Halaman 99-101.

[6] Subodh S, Sharma, Sumit K., Shweta A, Singh M., Vijay Y.K. 2009. Characterization of gas sensing behavior of multi walled carbon nanotube polyaniline composite films. International Journal of Hydrogen Energy, 34, Halaman 8444-8450.

[7] Supri A.Ghani, Heah Chen Y. 2010. Development of Carbon white-Carbon Black-Polyaniline Composite As a Conductive Polymer. Journal Physical Science.

[8] William F. Smith, J.H. 2006. Foundation of Materials Science and Enginering (Fourth ed) : McGraw. Hill Higher Education. 